\title{
Photosynthetic apparatus performance and anatomical modulations of Alcantarea imperialis (Bromeliaceae) exposed to selenium during in vitro growth
}

\author{
J.P.R. MARTINS ${ }^{+}$(iD), S.W. MOREIRA (iD), P.C.S. BRAGA (iD), L.T. CONDE (iD), R. CIPRIANO (iD), \\ A.R. FALQUETO (iD), and A.B.P.L. GONTIJO iD
}

Department of Agrarian and Biological Sciences, Federal University of Espirito Santo, Litorâneo 29932-540 São Mateus, ES, Brazil

\begin{abstract}
Elements not usually included in culture medium formulations, such as selenium (Se), may have beneficial effects on micropropagated plants. We evaluated the effects of Se on the physiological and anatomical responses of Alcantarea imperialis during in vitro culture. Plants were cultured in a medium containing a gradient of Se concentrations $(0,4,8$, 16 , or $32 \mu \mathrm{M} \mathrm{Se}$ ). After $56 \mathrm{~d}$, the growth traits, chlorophyll $a$ fluorescence, and root and leaf anatomy were analyzed. The fresh mass declined at the highest Se concentration. Higher Se concentrations induced bigger stomata, while the stomatal density decreased. Plants cultured with Se had improved PSII and PSI electron transport. This led to higher values of the total performance index. Thus, Se-induced plants showed a higher electron transport dynamics and energy conservation from water to PSI and developed anatomical traits that can favor tolerance to water deficit.
\end{abstract}

Keywords: bromeliad; chlorophyll $a$ fluorescence; electron transport; plant anatomy; plant tissue culture.

\section{Introduction}

In vitro techniques are often used for large-scale propagation of plants with high economic value or endangered status (Manokari et al. 2020, Priyadharshini et al. 2020, Kaur et al. 2021, Shekhawat et al. 2021). These techniques are particularly applied to ornamental species, including members of the Bromeliaceae family (Martins et al. 2015,

\section{Highlights}

- Plants grown with Se showed an improvement in PSII electron transport

- Se can induce plants with higher $\mathrm{PI}_{\text {total }}$ values during in vitro growth

- Se induced changes in the leaf anatomy benefiting the acclimatization stage
Received 9 June 2021

Accepted 6 September 2021

Published online 7 October 2021

${ }^{+}$Corresponding author phone: +55273121 1696

e-mail: jprmartinss@yahoo.com.br

Abbreviations: $\mathrm{Chl}$ - chlorophyll; $\mathrm{F}_{0}$ - minimal fluorescence yield of the dark-adapted state; $\mathrm{F}_{\mathrm{I}}$ - fluorescence intensity at $30 \mathrm{~ms}$; $\mathrm{F}_{\mathrm{J}}$ - fluorescence intensity at $2 \mathrm{~ms} ; \mathrm{F}_{\mathrm{K}}$ - fluorescence intensity at $0.3 \mathrm{~ms} ; \mathrm{F}_{\mathrm{K}} / \mathrm{F}_{\mathrm{J}}$ - ratio of fluorescence at $\mathrm{K}$ and $\mathrm{J}$ step of the induction curves; $F_{L}$ - fluorescence intensity at $0.15 \mathrm{~ms} ; \mathrm{F}_{\mathrm{m}}$ - maximal fluorescence yield of the dark-adapted state; $F_{P}-$ fluorescence peak; $F_{t}$ - fluorescence at time $t$ after the beginning of actinic illumination; $F_{V} / F_{0}$ - ratio of the de-excitation rate constants for photochemical and nonphotochemical events; OEC - oxygen-evolving complex; $\mathrm{PI}_{\text {total }}$ - total performance index, which measures the performance up until the final electron acceptors of PSI; RC/CS - total number of PSII active reaction centers; $\mathrm{S}_{\mathrm{m}} / \mathrm{t}_{\mathrm{Fmax}}$ - average fraction of open RC in the period of 0 to $t_{\mathrm{Fmax}}$ (time of maximum fluorescence production); $\mathrm{V}_{\mathrm{I}}-$ relative variable fluorescence at $30 \mathrm{~ms}$ (step I); $\mathrm{V}_{\mathrm{J}}-$ relative variable fluorescence at $2 \mathrm{~ms}($ step $\mathrm{J}) ; \mathrm{V}_{\mathrm{K}}$ - relative variable fluorescence at $0.3 \mathrm{~ms}\left(\right.$ step $\mathrm{K}$ ); $\mathrm{W}_{\mathrm{K}}$ - the damage to OEC; $\mathrm{W}_{\mathrm{L}}$ - indicates disturbance in the thylakoid membranes, reducing the energetic connectivity between the PSII units; $\delta R_{0}$ - efficiency/probability with which an electron from the intersystem electron carriers moves to reduce end electron acceptors at the PSI acceptor side $(\mathrm{RE}) ; \varphi \mathrm{D}_{0}-$ quantum yield of energy dissipation (at $\mathrm{t}=0) ; \varphi \mathrm{E}_{0}$ - quantum yield of electron transport $(\mathrm{at} t=0) ; \varphi \mathrm{P}_{0}=\mathrm{F}_{\mathrm{v}} / \mathrm{F}_{\mathrm{m}}-$ maximum quantum yield of primary photochemistry of PSII reaction center (at $\mathrm{t}=0) ; \varphi \mathrm{R}_{0}$ - quantum yield of reduction of end electron acceptors at the PSI acceptor side (RE); $\psi \mathrm{R}_{0}$ - efficiency/probability by which electrons move from PSII to the PSI acceptor side.

Acknowledgments: The authors would like to acknowledge the scholarship awarded by the CAPES (Coordination for the Improvement of Higher Education Personnel) and the FAPES (Espírito Santo State Research Foundation). The authors are also grateful to Luiz Carlos de Almeida Rodrigues for his technical assistance.

Conflict of interest: The authors declare that they have no conflict of interest. 
2018; Lando et al. 2016, Martínez-Estrada et al. 2019, Pakum et al. 2021). Alcantarea imperialis (Carrière) Harms is among the bromeliad species with ornamental interest. This species is widely employed in landscape projects (Andrade-Santos et al. 2021). A. imperialis is conventionally propagated by seeds, a method that is not efficient due to low seedling production and the need to conserve seeds. Besides these drawbacks, the plants require several decades to reach adulthood (flowering stage) (Versieux and Wanderley 2015, Tamaki et al. 2020). Thus, in vitro culture can be an alternative for this species' propagation, as already reported by Mollo et al. (2011), Kurita and Tamaki (2014), and Martins et al. (2020a). These authors verified the effect of temperature, macronutrients, and plant growth regulators as modulation factors of in vitro responses.

The modulation factors can have a negative impact on plant growth while still inside the in vitro containers, by inducing physiological disorders. Plants cultured in vitro can suffer from nonfunctional stomata, reduced water-use efficiency, and deficiencies in photosynthetic performance (Martins et al. 2018, Fortini et al. 2021, Shekhawat et al. 2021). These morphophysiological characteristics can compromise the final micropropagation step, known as acclimatization. The low capacity of in vitro plants to conserve water after transfer to ex vitro conditions can lead to desiccation and low survival rates (Asayesh et al. 2017). Therefore, the induction of in vitro plants with more efficient water use and uncompromised photosynthetic capacity is desirable.

In recent years, the application of elements not usually included in culture medium formulations, such as silicon (Si) and selenium (Se), have been shown to have beneficial effects on plants grown in vitro (Martins et al. 2019, Souza et al. 2019, Seliem et al. 2020, Silva et al. 2020a). These elements can influence in vitro morphogenesis as well as morphophysiology of micropropagated plants (e.g., improve the growth rate and photosynthetic pigment content of in vitro plants). The role of Se in the life cycle of plants is still controversial, but several lines of evidence indicate its potential as a biofortification agent when low concentrations are applied (Souza et al. 2019, Szarka et al. 2020, Sabatino et al. 2021). In contrast, Se excess can induce physiological disturbances or even plant death (Sotoodehnia-Korani et al. 2020, Szarka et al. 2020). Souza et al. (2019) and Martins et al. (2020b) already have reported the positive effects of Se on the physiological status of a bromeliad species (Billbergia zebrina) during in vitro culture.

The impacts of in vitro conditions can be verified by histological techniques. The characterization of anatomy via cross- and paradermical sections has proven to be an important tool to check the effects of culture medium components on in vitro plants (Rezende et al. 2018, Martins et al. 2019, 2020b). Likewise, the photosynthetic performance of in vitro plants can be monitored by measurement of chlorophyll (Chl) $a$ fluorescence (Martins et al. 2018, Rosa et al. 2018, Souza et al. 2019). This analysis also provides an overview of the stress status of plants through investigation of PSII and PSI performance (Rosa et al. 2018, Martins et al. 2020b).

Given the above, the study aimed to assess the physiological and anatomical responses of $A$. imperialis in the function of the Se concentrations during in vitro culture.

\section{Materials and methods}

Culture conditions and Se supplementation: Plants of Alcantarea imperialis previously multiplied in an in vitro culture medium with no plant growth regulators (Martins et al. 2020a) were used as explants. The explants were transferred to 500-ml glass containers holding $50 \mathrm{ml}$ of MS culture medium (Murashige and Skoog 1962) solidified with $5 \mathrm{~g} \mathrm{~L}^{-1}$ agar, supplemented with $30 \mathrm{~g} \mathrm{~L}^{-1}$ sucrose and $0,4,8,16$, or $32 \mu \mathrm{M} \mathrm{Se}\left(\mathrm{Na}_{2} \mathrm{SeO}_{3}\right)$. Five explants were placed in each glass container. The $\mathrm{pH}$ of all media was adjusted to 5.8 before autoclaving at $120^{\circ} \mathrm{C}$, for $20 \mathrm{~min}$. After inoculation in a laminar flow cabinet, the plant material was kept in a growth room for $56 \mathrm{~d}$ at $25 \pm 2{ }^{\circ} \mathrm{C}$ and 16/8 h light/dark photoperiod, under slim LED lamps (Blumenau ${ }^{\circledR} 36 \mathrm{~W} / 6500 \mathrm{~K}$ ) emitting $70 \mu \mathrm{mol}($ photon) $\mathrm{m}^{-2} \mathrm{~s}^{-1}$ of PAR.

Growth characteristics: After $56 \mathrm{~d}$, the plants were harvested and washed with distilled water to remove the culture medium adhering to the root surfaces. To determine their growth, 25 plants from each treatment were collected randomly, mixed, and divided into five pooled samples, and weighed on a precision scale. The fresh mass of the shoots (aerial part) and roots $(n=5)$ was determined separately [g per plant]. The number of roots per plant was also quantified.

Anatomical analysis: To characterize the anatomical changes of the leaves and roots of the plants grown under the in vitro conditions in response to the Se treatments, four A. imperialis plants from each treatment were used. All the samples were randomly collected after growth for $56 \mathrm{~d}$ and were fixed/stored in 50\% ethanol. The anatomical characterization was performed by examination of paradermal and cross-sections of leaves. For the roots, we performed cross-sections at $0.5 \mathrm{~cm}$ from the root base. All procedures were performed according to Martins et al. (2019). All the sections were viewed using a light microscope (L-2000AFluor, Bioval), and images were captured with a Leica EC3 camera (Wetzlar, Germany). The software UTHSCSA-Imagetool ${ }^{\circledR}$ was used to measure the anatomical characteristics shown in the photomicrographs. Two cross-sections per slide were photographed and analyzed per sample. For the characterization of the roots, we measured the thickness of the endodermis and the number of metaxylem vessels. For the leaves, the density of stomata $\left[\mathrm{mm}^{-2}\right]$ and trichomes $\left[\mathrm{mm}^{-2}\right]$, stomatal size $\left[\mathrm{mm}^{2}\right]$, the thickness of the chlorenchyma $[\mu \mathrm{m}]$, and hydrenchyma $[\mu \mathrm{m}]$ (abaxial and adaxial sides), as well as the number and diameter of vessel elements, were determined $(n=4)$. 
Chl $\boldsymbol{a}$ fluorescence measurement: The Chl $a$ fluorescence transients (the OJIP curves) were analyzed in 16 randomly selected plants. The measurements were performed after $56 \mathrm{~d}$ of Se treatment during in vitro culture, between 07:00 and 09:00 h, using a portable Handy PEA fluorimeter (Hansatech, King's Lynn, Norfolk, UK). The measurements were accomplished on the second completely expanded leaf in the central rosette after being dark-adapted for 30 min using a leaf clip (Hansatech). Double normalizations were performed for the $\mathrm{O}-\mathrm{P}$ and $\mathrm{O}-\mathrm{I}$ intervals $\left[\mathrm{V}_{\mathrm{OP}}=\right.$ $\left(F_{t}-F_{0}\right) /\left(F_{m}-F_{0}\right)$ and $V_{O I}=\left(F_{t}-F_{0}\right) /\left(F_{I}-F_{0}\right)$, respectively], as well as the kinetic differences between steps $\mathrm{O}$ and $\mathrm{I}$ $\left[\Delta \mathrm{V}_{\mathrm{OI}}=\mathrm{V}_{\mathrm{OI} \text { (treatment) }}-\mathrm{V}_{\mathrm{OI}(\text { control })}\right]$. Treatment without $\mathrm{Se}$ (0 $\mu \mathrm{M}$ Se) was used as the control. All OJIP curves, as well as the JIP test parameters, were analyzed according to the method proposed by Srivastava and Strasser (1996) and Strasser et al. (2004). The $\mathrm{W}_{\mathrm{L}}=\left(\mathrm{F}_{\mathrm{L}}-\mathrm{F}_{0}\right) /\left(\mathrm{F}_{\mathrm{K}}-\mathrm{F}_{0}\right)$ and $\mathrm{W}_{\mathrm{K}}=\left(\mathrm{F}_{\mathrm{K}}-\mathrm{F}_{0}\right) /\left(\mathrm{F}_{\mathrm{J}}-\mathrm{F}_{0}\right)$ were calculated according to Wang et al. (2016) and Zhang et al. (2018).

Statistical analysis: The experimental design was completely randomized, and the resulting data were submitted to analysis of variance (ANOVA), while the means (standard error - SE) were compared using Tukey's test at $5 \%$ significance. All analyses were performed using the SISVAR software.

\section{Results}

Growth traits: The Se treatments did not induce any visible physiological disturbances such as chlorosis and necrosis. However, plants grown in the presence of $\mathrm{Se}$ were slightly shorter on average, mainly at $32 \mu \mathrm{M}$ Se. The fresh mass of both aerial parts and roots declined under the highest Se concentration (Fig. 1A). The number of roots also decreased under high Se concentrations, although the decreases were only significant when the plants were exposed to 16 and $32 \mu \mathrm{M}$ Se (Fig. $1 B$ ).

Analysis of root and leaf anatomy: The treatments did not influence the analyzed traits of root anatomy (Fig. $2 A-E$ ). The roots had a similar thickness of the endodermis $(8.7 \pm 0.09 \mu \mathrm{m})$ as well as a number of metaxylem vessels $(5.7 \pm 0.3)$. However, Se concentrations had a significant impact on the leaf anatomy. The characteristics of stomata showed antagonistic responses. Higher Se concentrations induced bigger stomata, while the number of stomata per area decreased. A. imperialis leaves showed closed stomata, irrespective of the treatment. The density of trichomes did not differ between the treatments (Fig. $2 F-J$, Table 1).

The thickness of adaxial hydrenchyma was statistically similar for all treatments. In contrast, Se supplementation increased the abaxial hydrenchyma thickness. The chlorenchyma was thinner under Se exposure. Finally, xylem vessel traits were similar in all Se treatments (Fig. $2 K-T$, Table 1).

Chl $\boldsymbol{a}$ fluorescence: The Se concentrations also affected the performance of the photosynthetic apparatus. The values of $\mathrm{V}_{\mathrm{K}}$ did not show any differences. On the other

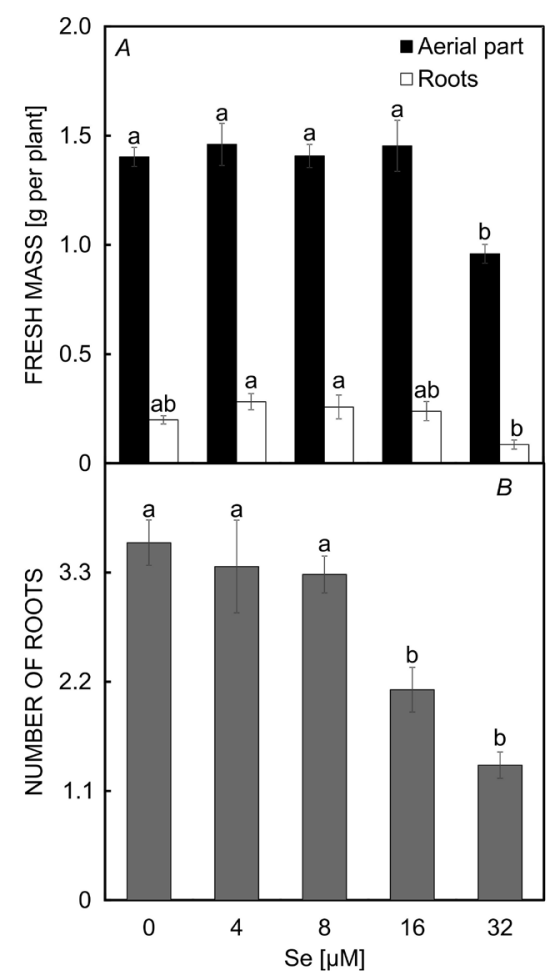

Fig. 1. Fresh mass $(A)$ and number of roots $(B)$ of Alcantarea imperialis plants grown in vitro in function of concentrations of $\mathrm{Se}$ in the medium. Means $\pm \mathrm{SE}(n=5)$ followed by the same letter do not differ significantly by the Tukey's test $(p<0.05)$.

hand, the values of $V_{\mathrm{J}}$ and $\mathrm{V}_{\mathrm{I}}$ were lower with Se exposure (Fig. 3).

The kinetic differences between the $\mathrm{O}(20 \mu \mathrm{s})$ and I (30 ms) phases were evaluated. All the Se treatments produced negative bands $\left(\mathrm{V}_{\mathrm{OI}} \leq 1.0\right)$. The lowest values were observed in the plants cultured with 8 and $16 \mu \mathrm{M} \mathrm{Se}$ (Fig. 4A). In addition, the curves of the highest amplitude observed for the relative fluorescence at $\mathrm{V}_{\mathrm{OI}} \geq 1.0$ were obtained in the interval from 30 to $800 \mathrm{~ms}$ for all plants grown with Se (Fig. 4B).

Regarding the JIP test parameters, the values of $\mathrm{W}_{\mathrm{L}}$, $\mathrm{W}_{\mathrm{K}}, \mathrm{F}_{\mathrm{K}} / \mathrm{F}_{\mathrm{J}}, \mathrm{F}_{\mathrm{V}} / \mathrm{F}_{0}, \varphi \mathrm{P}_{0}, \varphi \mathrm{D}_{0}$, and $\mathrm{RC} / \mathrm{CS}_{\mathrm{m}}$ were similar among the treatments. The values of $\varphi \mathrm{E}_{0}$ were higher in plants under 8 and $16 \mu \mathrm{M}$ in comparison with the control plants $(0 \mu \mathrm{M} \mathrm{Se})$. Likewise, plants cultured with 4,8 , and $16 \mu \mathrm{M}$ Se had higher $S_{m} / t_{F m a x}$ values. The parameters related to PSI activity $\left(\varphi \mathrm{R}_{0}, \psi \mathrm{R}_{0}, \delta \mathrm{R}_{0}\right)$ showed increased values in comparison with the plants grown without $\mathrm{Se}$ (Fig. 5).

The $\Delta V_{I P}=\left(F_{P}-F_{I}\right) /\left(F_{P}-F_{0}\right)$ increased with Se presence (Fig. 6A). Likewise, $\mathrm{PI}_{\text {total }}$ increased gradually with rising Se concentrations, and the highest was in those cultured with 8 and $16 \mu \mathrm{M}$ Se (Fig. $6 B$ ).

\section{Discussion}

In this study, we report how Se can influence the growth, anatomical and physiological traits of $A$. imperialis. 
Plants exposed to concentrations above $16 \mu \mathrm{M}$ Se showed changes in growth characteristics (fresh mass of aerial part and roots) that could be misinterpreted as a symptom of toxicity induced by excessive Se. In most cases, a reduction of biomass accumulation is the first sign that plants have experienced stressful conditions, and this response normally is correlated with stunted growth and/or physiological disturbances (Kolbert et al. 2019, Shafiq et al. 2019, Souza et al. 2019). The number of roots of $A$. imperialis plants also decreased under high Se concentrations. The root system is highly affected by

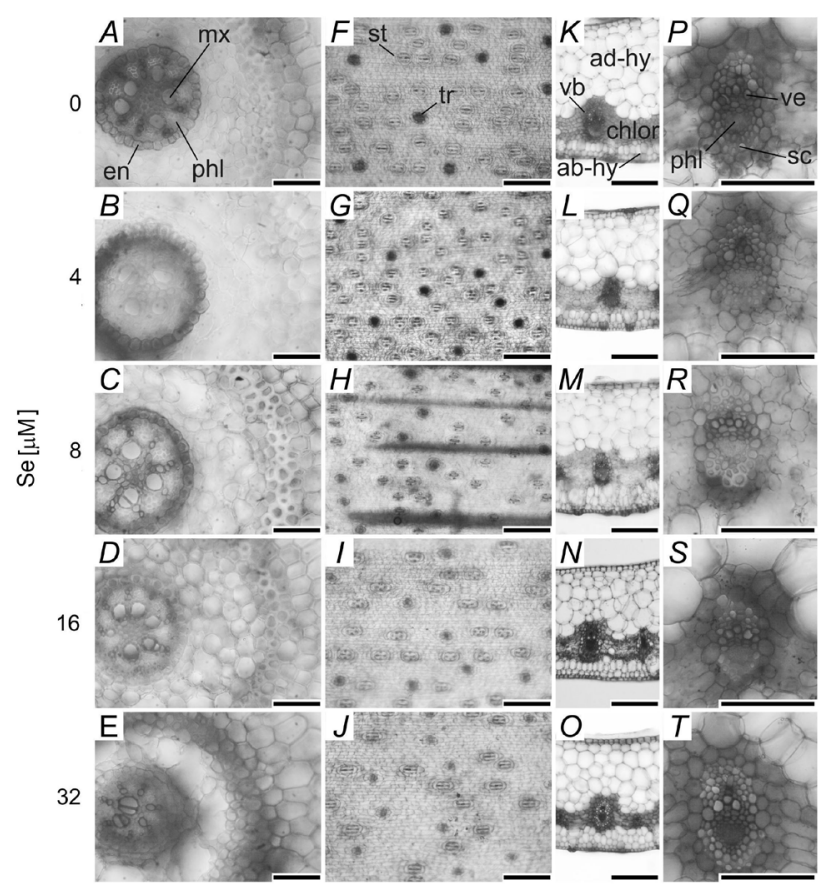

Fig. 2. Paradermal and cross-sections of Alcantarea imperialis leaves and roots at $56 \mathrm{~d}$ of growth in medium containing 0 , $4,8,16$ or $32 \mu \mathrm{M}$ Se during in vitro culture. ab-hy - abaxial hydrenchyma; ad-hy - adaxial hydrenchyma; chlor chlorenchyma; en - endodermis; mx - metaxylem vessel; phl - phloem; sc - sclerenchyma; st - stoma; tr - trichome; vb vascular bundle; ve - vessel element. Bars $=100 \mu \mathrm{m}$.
Se because it usually is the first point of contact with this element in the environment (Kolbert et al. 2016). Se can affect root architecture (number and length of lateral roots) since it modulates the expression of genes associated with the biosynthesis of plant hormones (Jia et al. 2018, Malheiros et al. 2019). Since A. imperialis plants did not show clear signs of physiological stress after $56 \mathrm{~d}$ of culture, the modulations of the growth traits could be related to another factor. Malheiros et al. (2019) observed that Se can interfere with auxin and ethylene balance and also is negatively related to the expression of genes associated with auxin transport. Since auxins are responsible not only for rooting but also for cell enlargement of all plant organs (Tian et al. 2018, Toungos 2018, Ma and Li 2019), a decrease in size and mass of $A$. imperialis may be a hormonal response instead of a reflection of stress.

In this work, the leaf and root anatomy of the plants were in accordance with previous reports of $A$. imperialis as well as other species of the Bromeliaceae family (Zorger et al. 2019, Martins et al. 2020a, Silva et al. 2020b, Faria et al. 2021). Even though Se modulated the root architecture of $A$. imperialis plants, this metalloid did not interfere with the roots' anatomical traits. Plants under stress promoted by an element (e.g., cadmium, zinc, lead, and sodium) in contact with the roots may show alterations in thickness of the endodermis and/or a number of xylem vessels (Rodrigues et al. 2017, Al-Aradi et al. 2020, Baroni et al. 2020). The endodermis has a protective function because it acts as an apoplastic barrier controlling the radial transport of water and ions, to reduce the entry of contaminants from the surroundings to the vascular cylinder (Rodrigues et al. 2017). A smaller number of metaxylem vessels of roots can also act to control element translocation (Martins et al. 2016, 2019). Since the plants did not have root anatomical changes associated with Se uptake, the results suggest that stunted growth was not a stress response. The absence of stress was confirmed by the Chl $a$ fluorescence analysis. In addition, no changes were found in the xylem traits in the leaves, confirming the plants did not have anatomical mechanisms to regulate $\mathrm{Se}$ absorption and translocation.

The Se exposure induced changes in the leaf anatomy that can benefit the acclimatization stage. On the leaf surface, the stomata had characteristics indicating better

Table 1. Anatomical structures of Alcantarea imperialis plants grown in vitro in function of concentrations of Se $[\mu \mathrm{M}]$ in the medium. For each anatomical trait, means $\pm \operatorname{SE}(n=4)$ followed by the same letter do not differ significantly according to the Tukey's test $(p<0.05)$.

\begin{tabular}{llllll}
\hline Anatomical traits & $0 \mu \mathrm{M} \mathrm{Se}$ & $4 \mu \mathrm{M} \mathrm{Se}$ & $8 \mu \mathrm{M} \mathrm{Se}$ & $16 \mu \mathrm{M} \mathrm{Se}$ & $32 \mu \mathrm{M} \mathrm{Se}$ \\
\hline Stomatal size $\left[\mu \mathrm{m}^{2}\right]$ & $1,316.5 \pm 34.3^{\mathrm{b}}$ & $1,450.6 \pm 42.3^{\mathrm{ab}}$ & $1,567.0 \pm 35.3^{\mathrm{a}}$ & $1,583.8 \pm 64.4^{\mathrm{a}}$ & $1,671.9 \pm 80.1^{\mathrm{a}}$ \\
Stomatal density $\left[\mathrm{mm}^{-2}\right]$ & $66.4 \pm 2.9^{\mathrm{a}}$ & $68.2 \pm 3.3^{\mathrm{a}}$ & $58.8 \pm 5.0^{\mathrm{ab}}$ & $35.0 \pm 8.7^{\mathrm{b}}$ & $38.7 \pm 5.5^{\mathrm{b}}$ \\
Density of trichomes $\left[\mathrm{mm}^{-2}\right]$ & $12.1 \pm 1.6^{\mathrm{a}}$ & $13.5 \pm 1.1^{\mathrm{a}}$ & $12.4 \pm 0.7^{\mathrm{a}}$ & $13.7 \pm 1.6^{\mathrm{a}}$ & $18.2 \pm 2.9^{\mathrm{a}}$ \\
Adaxial hydrenchyma $[\mu \mathrm{m}]$ & $331.8 \pm 34.7^{\mathrm{a}}$ & $313.2 \pm 20.0^{\mathrm{a}}$ & $261.3 \pm 13.8^{\mathrm{a}}$ & $331.2 \pm 17.8^{\mathrm{a}}$ & $301.8 \pm 15.4^{\mathrm{a}}$ \\
Chlorenchyma $[\mu \mathrm{m}]$ & $100.1 \pm 2.4^{\mathrm{a}}$ & $85.2 \pm 1.8^{\mathrm{b}}$ & $94.8 \pm 4.8^{\mathrm{ab}}$ & $84.4 \pm 3.5^{\mathrm{b}}$ & $81.7 \pm 3.0^{\mathrm{b}}$ \\
Abaxial hydrenchyma $[\mu \mathrm{m}]$ & $73.7 \pm 5.2^{\mathrm{b}}$ & $83.9 \pm 4.7^{\mathrm{ab}}$ & $99.2 \pm 2.8^{\mathrm{a}}$ & $97.3 \pm 7.7^{\mathrm{ab}}$ & $87.2 \pm 6.5^{\mathrm{ab}}$ \\
Diameter of xylem vessels $[\mu \mathrm{m}]$ & $8.9 \pm 0.1^{\mathrm{a}}$ & $10.5 \pm 0.2^{\mathrm{a}}$ & $9.5 \pm 0.3^{\mathrm{a}}$ & $9.3 \pm 0.5^{\mathrm{a}}$ & $9.7 \pm 0.4^{\mathrm{a}}$ \\
Number of xylem vessels & $3.4 \pm 0.8^{\mathrm{a}}$ & $3.7 \pm 0.6^{\mathrm{a}}$ & $3.7 \pm 0.3^{\mathrm{a}}$ & $3.9 \pm 0.4^{\mathrm{a}}$ & $3.4 \pm 0.6^{\mathrm{a}}$ \\
\hline
\end{tabular}




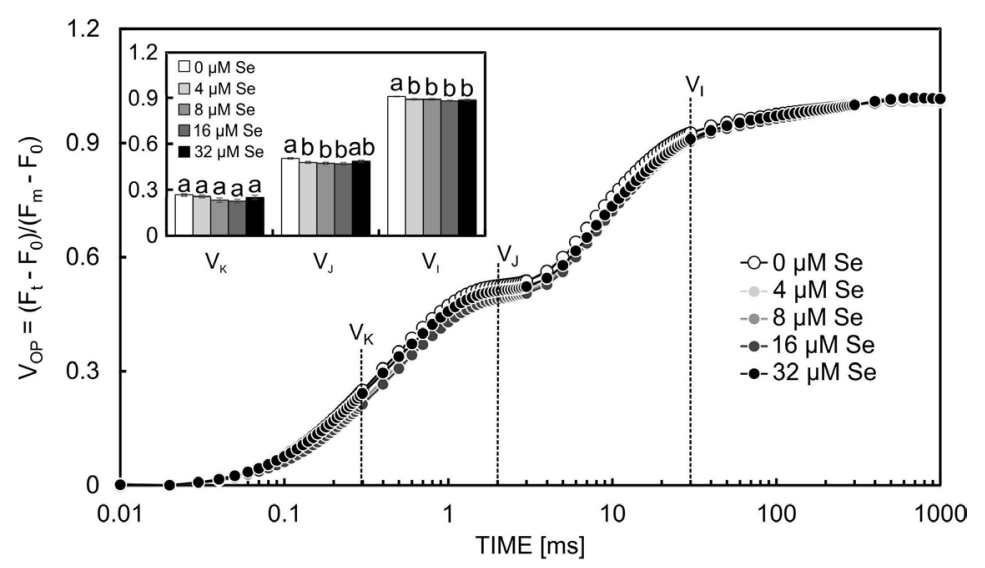

Fig. 3. Relative variable fluorescence between $F_{0}$ and $\mathrm{F}_{\mathrm{P}}\left(\mathrm{V}_{\mathrm{OP}}\right)$ of Alcantarea imperialis plants grown in media with different Se concentrations. For each point of relative variable fluorescence, means \pm SE $(n=16)$ followed by the same letter do not differ significantly according to the Tukey's test $(p<0.05)$. $\mathrm{V}_{\mathrm{I}}$ - relative variable fluorescence at $30 \mathrm{~ms}$ (step I); $\mathrm{V}_{\mathrm{J}}$ - relative variable fluorescence at $2 \mathrm{~ms}$ (step J); $\mathrm{V}_{\mathrm{K}}$ - relative variable fluorescence at $0.3 \mathrm{~ms}$ (step K).

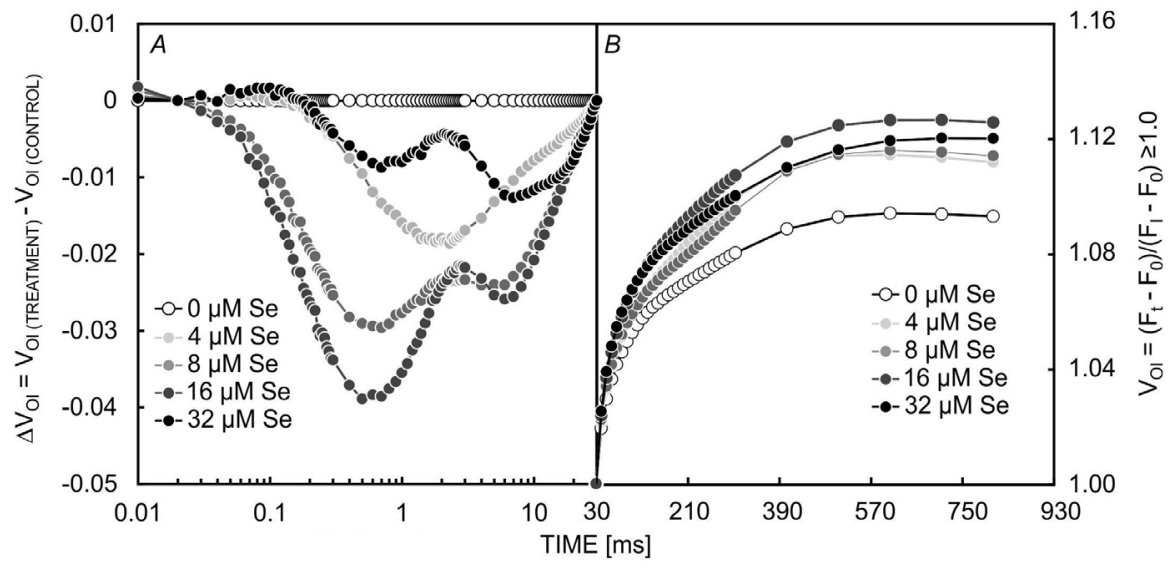

Fig. 4. Chlorophyll $a$ fluorescence transient points between the $\mathrm{O}-\mathrm{I}$ of Alcantarea imperialis plants grown in media with different $\mathrm{Se}$ concentrations $(n=16)$. $(A)$ Kinetic differences between $\mathrm{F}_{0}$ and $\mathrm{F}_{\mathrm{I}}$, where $\mathrm{V}_{\mathrm{OI}}=\left(\mathrm{F}_{\mathrm{t}}-\mathrm{F}_{0}\right) /\left(\mathrm{F}_{\mathrm{I}}-\mathrm{F}_{0}\right)$ is $\mathrm{V}_{\mathrm{OI}} \leq 1$ (range of 0.01 to $30 \mathrm{~ms}$ ). (B) Normalization between $\mathrm{F}_{0}$ and $\mathrm{F}_{\mathrm{I}}$, where $\mathrm{V}_{\mathrm{OI}} \geq 1$ is in the range of 30 to $800 \mathrm{~ms}$.

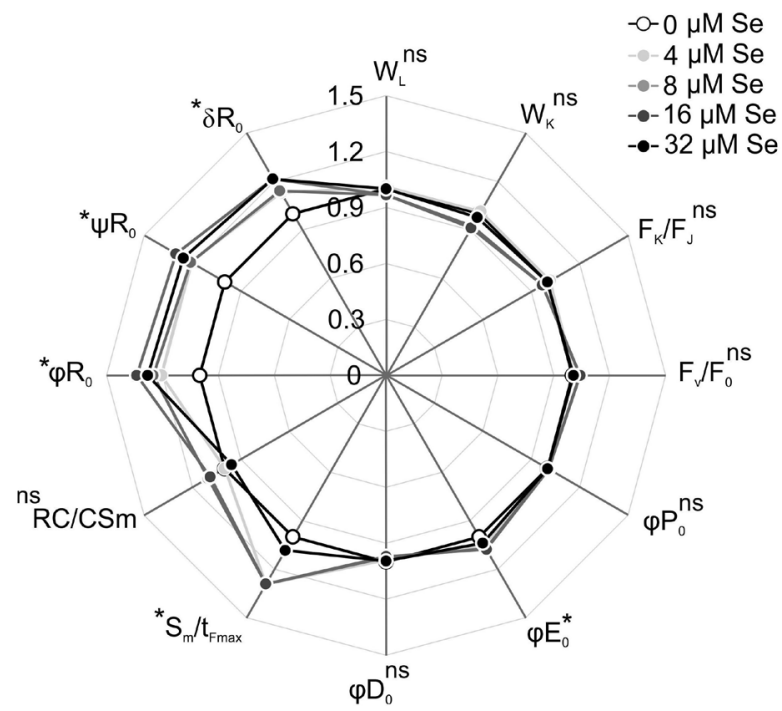

water-use efficiency. The stomatal dynamics is the key for water-use efficiency under adverse conditions (Asayesh et al. 2017, Kiani-Pouya et al. 2019). Regardless of the treatments, all plants showed closed stomata. It can mean the stomata remained functional even under in vitro conditions. Nonfunctional stomata (widely open) have often been reported concerning in vitro propagated plants,
Fig. 5. The JIP test parameters of Alcantarea imperialis plants grown in media with different Se concentrations. Means $\pm \mathrm{SE}$ $(n=16)$ followed by an asterisk $(*)$ are significantly different according to the Tukey's test $(p<0.05)$. ns - no significant difference. The data were normalized with the control $(0 \mu \mathrm{M} \mathrm{Se})$ equal to 1 . $\mathrm{F}_{\mathrm{K}} / \mathrm{F}_{\mathrm{J}}$ - ratio of fluorescence at $\mathrm{K}$ and $\mathrm{J}$ step of the induction curves; $\mathrm{F}_{\mathrm{V}} / \mathrm{F}_{0}$ - ratio of the de-excitation rate constants for photochemical and nonphotochemical events; $\mathrm{RC} / \mathrm{CS}_{\mathrm{m}}$ - total number of PSII active reaction centers; $\mathrm{S}_{\mathrm{m}} / \mathrm{t}_{\mathrm{Fmax}}$ - average fraction of open $\mathrm{RC}$ in the period of 0 to $t_{\mathrm{Fmax}}$ (time of maximum fluorescence production); $\mathrm{W}_{\mathrm{K}}$ - the damage to OEC; $\mathrm{W}_{\mathrm{L}}$ - indicates disturbance in the thylakoid membranes, reducing the energetic connectivity between the PSII units; $\varphi \mathrm{P}_{0}-$ maximum quantum yield of primary photochemistry (at $\mathrm{t}=0) ; \varphi \mathrm{E}_{0}$ - quantum yield of electron transport (at $\mathrm{t}=0$ ); $\varphi \mathrm{D}_{0}-$ quantum yield of energy dissipation (at $t=0) ; \varphi R_{0}-$ quantum yield of reduction of end electron acceptors at the PSI acceptor side (RE); $\delta \mathrm{R}_{0}$ - efficiency/probability with which an electron from the intersystem electron carriers moves to reduce end electron acceptors at the PSI acceptor side (RE); $\psi \mathrm{R}_{0}$ - efficiency/probability by which electrons move from PSII to the PSI acceptor side.

and this anatomical disorder can compromise the acclimatization stage due to faster dehydration of the plants (Manokari et al. 2020, Priyadharshini et al. 2020, Shekhawat et al. 2021). In our work, the stomatal density was negatively correlated with a stomatal size. A reduction in the stomatal density may represent a primary mechanism by which plants can optimize water-use efficiency because 


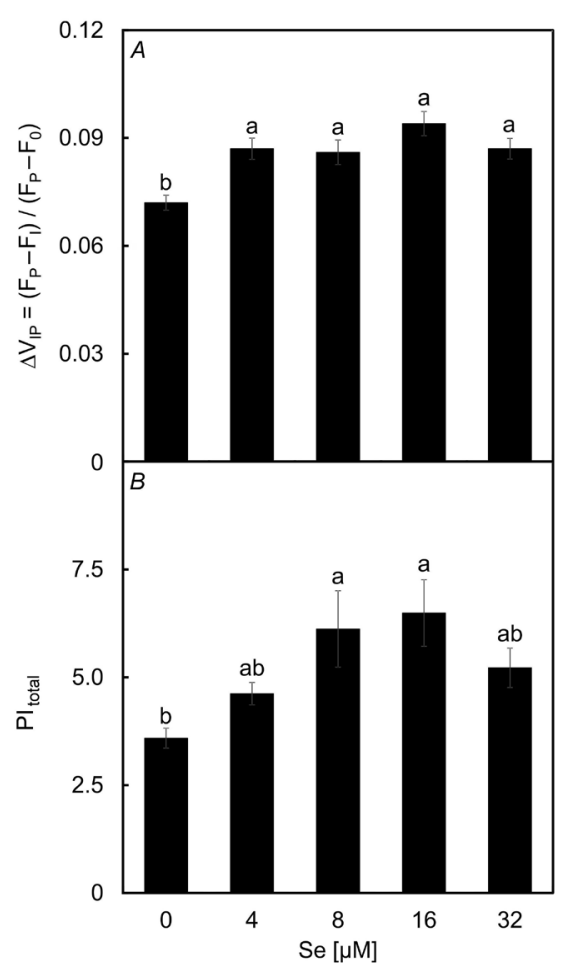

Fig. 6. Relative variable fluorescence between the I-P points $\left(\Delta \mathrm{V}_{\mathrm{IP}}\right)(A)$ and total performance index $\left(\mathrm{PI}_{\text {total }}\right)(B)$ of Alcantarea imperialis plants grown in vitro in function of concentrations of $\mathrm{Se}$ in the medium. Means $\pm \mathrm{SE}(n=16)$ followed by the same letter do not differ significantly according to the Tukey's test $(p<0.05)$.

this characteristic can decrease the stomatal conductance (Kiani-Pouya et al. 2019). Concerning the stomatal size, it has been reported that bigger stomata have lower water-use efficiency as a function of a slower closing rate (Drake et al. 2013, Raven 2014). However, ElliottKingston et al. (2016) reported that small stomata do not always close faster than large ones. Moreover, smaller stomata do not always favor photosynthesis (Zhang et al. 2019). We suggest that an increment in the size of the stomata is a compensation strategy (tradeoff) for reduced stomatal density, which can maintain a proper balance between $\mathrm{CO}_{2}$ assimilation and water loss. Therefore, the stomatal characteristics presented in A. imperialis plants cultured with Se seem to be promising for plants grown under adverse conditions, such as during the initial acclimatization steps.

Still, concerning the water status, bromeliads have a specialized tissue for water storage called hydrenchyma. This tissue can be crucial for ex vitro growth after transfer to new conditions by supporting water maintenance (Martins et al. 2015, 2018). In this work, the exposure of plants to Se induced leaves with slightly thicker hydrenchyma (abaxial side), which can act to maintain the proper water status. In contrast, plants cultured with Se tended to have thinner chlorenchyma. Although we did not measure the size of the chlorenchyma cells, the number of layers did not vary among the treatments (6-7 cell layers). Thus, the reduction in thickness of this tissue was due to the formation of smaller cells. Smaller Chl parenchyma cells can resist turgor pressure better than large ones. This may offer an advantage under water-deficit conditions by contributing more effectively to turgor maintenance, which can be interpreted as a tolerance mechanism of the leaves to maintain tissue turgor (Boughalleb et al. 2015). Therefore, the leaves of $A$. imperialis plants with larger water-storage cells and smaller chlorenchyma cells can be helpful during the stress period that can occur just after transfer to ex vitro conditions.

The morphological changes verified after $56 \mathrm{~d}$ of culture did not cause physiological disturbances at that time interval. This was demonstrated by the Chl $a$ fluorescence transient and parameters of the JIP test. Plants under stress may show lower $\varphi \mathrm{P}_{0}$ values as well as higher values of $\varphi \mathrm{D}_{0}$, indicating energy dissipation (Umar et al. 2019, Santos et al. 2020, Sousaraei et al. 2021). According to Bolhar-Nordenkampf et al. (1989), plants grown under nonstress conditions usually show values of $\varphi \mathrm{P}_{0} \geq 0.75$. In this study, the $A$. imperialis plants had $\varphi \mathrm{P}_{0}$ values greater than 0.78 , meaning there was no sign of photoinhibition at $56 \mathrm{~d}$ of growth, irrespective of Se treatments. Besides no changes in these parameters, the plants also had similar values of $\mathrm{W}_{\mathrm{L}}, \mathrm{V}_{\mathrm{K}}, \mathrm{F}_{\mathrm{K}} / \mathrm{F}_{\mathrm{J}}, \mathrm{F}_{\mathrm{V}} / \mathrm{F}_{0}$, and $\mathrm{W}_{\mathrm{K}}$, together denoting no damage to the functional and structural integrity of the thylakoid membranes and in the oxygen-evolving complex (OEC) (Oukarroum et al. 2009, Zhang et al. 2018, Faseela et al. 2020, Martins et al. 2020b).

Plants cultured with Se showed an improvement of PSII electron transport, as indicated by the reduced values of $\mathrm{V}_{\mathrm{J}}$ and increased values of $\varphi \mathrm{E}_{0}$. A decline of the J-step level $\left(\mathrm{V}_{\mathrm{J}}\right)$ can be attributed to a lower accumulation of reduced plastoquinone $A\left(Q_{A}\right)$ electron acceptor of PSII $\mathrm{RC}$. This is interpreted as a higher rate of electron flow from $\mathrm{Q}_{\mathrm{A}}$ to the plastoquinone $\mathrm{B}\left(\mathrm{Q}_{\mathrm{B}}\right)$ electron acceptor of PSII RC and expressed as increased values of $\varphi \mathrm{E}_{0}$ (Martins et al. 2019, Guo et al. 2020a). This lower accumulation of $\mathrm{Q}_{\mathrm{A}}^{-}$was reflected in higher values of $\mathrm{S}_{\mathrm{m}} / \mathrm{t}_{\mathrm{Fmax}}$. Thus, the higher values of $S_{m} / t_{F \max }$, verified in plants grown with $S e$, can indicate an accelerated electron transport beyond $\mathrm{Q}_{\mathrm{A}}{ }^{-}$ and a bigger pool of oxidized electron acceptors between PSII and PSI.

The double normalization method allowed us to verify the changes from the I step. The kinetic changes between $\mathrm{O}$ and $\mathrm{I}$ steps $\left(\mathrm{V}_{\mathrm{OI}} \leq 1.0\right)$ can indicate the process of exciton trapping and reduction of plastoquinone pool (Yusuf et al. 2010, Khalid et al. 2015, Ayyaz et al. 2020). The negative amplitudes (displayed as kinetic differences $-\Delta \mathrm{V}_{\mathrm{OI}}$ ) verified in plants cultured with Se (Fig. $4 A$ ) indicated that this element affected the process involving the trapping of the exciton to the reduction of PQ and those plants could maintain the maximum PQ reduction rate (Adamski et al. 2011). $\mathrm{V}_{\mathrm{OI}} \geq 1$ is related to the $\mathrm{I}-\mathrm{P}$ phase and reveals the changes in the electron flux from the plastoquinol $\left(\mathrm{PQH}_{2}\right)$ to the end electron acceptors on the PSI acceptor side (Yusuf et al. 2010, Braga et al. 2020, Naciri et al. 2021). The higher amplitudes observed through the normalization between the $\mathrm{O}-\mathrm{I}$ steps $\left(\mathrm{V}_{\mathrm{OI}} \geq 1.0\right)$ in 
Se-treated plants (Fig. 4B) are also an indication of the dynamic modulations of the electron transport from the intersystem to the PSI and can be interpreted as an increase in the pool size of the final electron acceptors from the acceptor side of the PSI (Souza et al. 2019).

Further regarding step I, decreased values of $\mathrm{V}_{\mathrm{I}}$ were observed in $A$. imperialis plants cultured with Se. An increase of $\mathrm{V}_{\mathrm{I}}$ may indicate partial inhibition on the acceptor side of PSII due to a relative change in the $\mathrm{Q}_{\mathrm{B}}$-nonreducing PSII RCs (Jiang et al. 2008). It can result in a lower efficiency/probability of electron movement from PSII to the PSI acceptor side (Martins et al. 2020b). Therefore, the decreased values of $\mathrm{V}_{\mathrm{I}}$, verified in this work, corresponded to a relative improvement of electron transport to PSI, which was reflected in increased values of $\psi \mathrm{R}_{0}$ and $\varphi \mathrm{R}_{0}$. These results may also reflect the increased electrons flux toward the cyclic flow to improve metabolic energy (ATP) to plants (Fang et al. 2020). Lower values of $\psi \mathrm{R}_{0}$ are associated with reduced PSI activity (Rastogi et al. 2019, Faseela et al. 2020). In our study, A. imperialis plants had higher $\psi \mathrm{R}_{0}$ values, which can denote a higher efficiency or probability of trapped electron transfer from PSII to PSI.

The subsequent significant alterations were found in the parameters explaining the state of end electron acceptors on the PSI acceptor side $\left(\Delta \mathrm{V}_{\mathrm{IP}}, \varphi \mathrm{R}_{0}\right.$, and $\left.\delta \mathrm{R}_{0}\right)$, indicating that Se has potential sites of action in the intersystem and PSI, as suggested by Souza et al. (2019). $\Delta \mathrm{V}_{\mathrm{IP}}$ is an indicator of the relative contribution of the I-P phase to the Chl $a$ fluorescence emission curve and abundance of PSI with respect to PSII (Ceppi et al. 2012, Souza et al. 2019). In this study, plants cultured with Se had higher values of $\Delta \mathrm{V}_{\mathrm{IP}}$, which may have reflected increments in PSI units. These plants also showed higher values of $\varphi R_{0}$ and $\delta R_{0}$. These parameters are associated with PSI performance (Lotfi et al. 2018, Souza et al. 2019, Guo et al. 2020b) and have a direct impact on $\mathrm{PI}_{\text {total }}$ values. Higher values of $\mathrm{PI}_{\text {total }}$ can indicate an improvement in the potential energy conservation ability of the photons absorbed by PSII for the reduction of the electron acceptors in the intersystem and reduction of the final acceptors in PSI (Yusuf et al. 2010). Thus, our results obtained from the J step to P step suggested a greater reduction of the electron transport chain and an enhancement in the transport dynamics and energy conservation of the photosynthetic apparatus, mainly in plants cultured with the concentration range of $8-16 \mu \mathrm{M}$ Se.

Conclusion: Se can modulate the physiological and anatomical responses of $A$. imperialis. The plants grown without $\mathrm{Se}$ exhibited poorer overall performance of photosynthetic apparatus than those cultured with this element. The positive effects of Se exposure during in vitro culture were reflected in better transport dynamics and energy conservation from the PSII to PSI, mainly in plants cultured with the concentration range of $8-16 \mu \mathrm{M}$ Se. In addition, plants cultured with Se exposure showed anatomical traits that can favor the tolerance of water deficit.

\section{References}

Adamski J.M., Peters J.A., Danieloski R., Bacarin M.A.: Excess iron-induced changes in the photosynthetic characteristics of sweet potato. - J. Plant Physiol. 168: 2056-2062, 2011.

Andrade-Santos S.V., Young J.L.M., Ramiro L.K. et al.: Effect of nitrate concentration on plant growth and anthocyanin accumulation in the ornamental bromeliad Alcantarea imperialis. - J. Plant Nutr. 44: 181-195, 2021.

Al-Aradi H.J., Al-Najjar M.A., Awad K.M., Abass M.H.: Combination effect between lead and salinity on anatomical structure of date palm Phoenix dactylifera L. seedlings. Agrivita 42: 487-498, 2020.

Asayesh Z.M., Vahdati K., Aliniaeifard S.: Investigation of physiological components involved in low water conservation capacity of in vitro walnut plants. - Sci. Hortic.-Amsterdam 224: 1-7, 2017.

Ayyaz A., Amir M., Umer S. et al.: Melatonin induced changes in photosynthetic efficiency as probed by OJIP associated with improved chromium stress tolerance in canola (Brassica napus L.). - Heliyon 6: e04364, 2020.

Baroni G.D.R., Pereira M.P., Corrêa F.F. et al: Cadmium tolerance during seed germination and seedling growth of Schinus molle (Anacardiaceae). - Floresta Ambiente 27: e20170502, 2020.

Bolhar-Nordenkampf H.R., Long S.P., Baker N.R. et al.: Chlorophyll fluorescence as a probe of the photosynthetic competence of leaves in the field: a review of current instrumentation. - Funct. Ecol. 3: 497-514, 1989.

Boughalleb F., Abdellaoui R., Hadded Z., Neffati M.: Anatomical adaptations of the desert species Stipa lagascae against drought stress. - Biologia 70: 1042-1052, 2015.

Braga P.C.S., Martins J.P.R., Bonomo R. et al.: Differential response of photosystem II and I photochemistry in leaves of two Crambe abyssinica Hochst lineages submitted to water deficit. - Photosynthetica 58: 1122-1129, 2020.

Ceppi M.G., Oukarroum A., Çiçek N. et al.: The IP amplitude of the fluorescence rise OJIP is sensitive to changes in the photosystem I content of leaves: a study on plants exposed to magnesium and sulfate deficiencies, drought stress and salt stress. - Physiol. Plantarum 144: 277-288, 2012.

Drake P.L., Froend R.H., Franks P.J.: Smaller, faster stomata: Scaling of stomatal size, rate of response, and stomatal conductance. - J. Exp. Bot. 64: 495-505, 2013.

Elliott-Kingston C., Haworth M., Yearsley J.M. et al: Does size matter? Atmospheric $\mathrm{CO}_{2}$ may be a stronger driver of stomatal closing rate than stomatal size in taxa that diversified under low $\mathrm{CO}_{2}$. - Front. Plant Sci. 7: 1253, 2016.

Fang Y., Jiang Z., Zhao C. et al.: Efficient heat dissipation and cyclic electron flow confer daily air exposure tolerance in the intertidal seagrass Halophyla beccarii Asch. - Front. Plant Sci. 11: 571627, 2020.

Faria C.G., Silva A.S., Melo R.K.P. et al.: Leaf anatomy of Vriesea (Tillandsioideae-Bromeliaceae). - Brittonia 73: 27 52, 2021.

Faseela P., Sinisha A.K., Brestič M., Puthur J.T.: Chlorophyll a fluorescence parameters as indicators of a particular abiotic stress in rice. - Photosynthetica 58: 293-300, 2020.

Fortini E.A., Batista D.S., Mamedes-Rodrigues T.C. et al.: Gas exchange rates and sucrose concentrations affect plant growth and production of flavonoids in Vernonia condensata grown in vitro. - Plant Cell Tiss. Org. Cult. 144: 593-605, 2021.

Guo Y.Y., Li H.J., Liu J. et al:: Melatonin alleviates droughtinduced damage of photosynthetic apparatus in maize seedlings. - Russ. J. Plant Physiol. 67: 312-322, 2020 b.

Guo Y., Zhang Y., Lu Y. et al.: Effect of AtLFNR1 deficiency on 
chlorophyll $a$ fluorescence rise kinetics OJIP of Arabidopsis. Photosynthetica 58: 391-398, 2020a.

Jia H., Song Z., Wu F. et al.: Low selenium increases the auxin concentration and enhances tolerance to low phosphorous stress in tobacco. - Environ. Exp. Bot. 153: 127-134, 2018.

Jiang H.X., Chen L.S., Zheng J.G. et al.: Aluminum-induced effects on Photosystem II photochemistry in Citrus leaves assessed by the chlorophyll $a$ fluorescence transient. - Tree Physiol. 28: 1863-1871, 2008.

Kaur K., Singh P., Kaur K. et al.: Development of robust in vitro culture protocol for the propagation of genetically and phytochemically stable plants of Withania somnifera (L.) Dunal (Ashwagandha). - Ind. Crop. Prod. 166: 113428, 2021.

Khalid A., Athar H.U.R., Zafar Z.U. et al.: Photosynthetic capacity of canola (Brassica napus L.) plants as affected by glycinebetaine under salt stress. - J. Appl. Bot. Food Qual. 88: 78-86, 2015.

Kiani-Pouya A., Rasouli F., Bazihizina N. et al.: A large-scale screening of quinoa accessions reveals an important role of epidermal bladder cells and stomatal patterning in salinity tolerance. - Environ. Exp. Bot. 168: 103885, 2019.

Kolbert Z., Lehotai N., Molnár Á., Feigl G.: "The roots" of selenium toxicity: A new concept. - Plant Signal. Behav. 11: e1241935, 2016.

Kolbert Z., Molnár Á., Feigl G., Van Hoewyk D.: Plant selenium toxicity: Proteome in the crosshairs. - J. Plant Physiol. 232: 291-300, 2019.

Kurita F.M.K., Tamaki V.: In vitro growth of the bromeliad Alcantarea imperialis (Carrière) Harms with different concentrations of nitrogen. - Acta Sci. Biol. Sci. 36: 279-285, 2014.

Lando A.P., Wolfart M.R., Fermino Jr. P.C.P., Santos M.: Structural effects on Cattleya xanthina leaves cultivated in vitro and acclimatized ex vitro. - Biol. Plantarum 60: 219225, 2016.

Lotfi R., Kalaji H.M., Valizadeh G.R. et al.: Effects of humic acid on photosynthetic efficiency of rapeseed plants growing under different watering conditions. - Photosynthetica 56: 962-970, 2018.

Ma L., Li G.: Auxin-dependent cell elongation during the shade avoidance response. - Front. Plant Sci. 10: 914, 2019.

Malheiros R.S.P., Costa L.C., Ávila R.T. et al.: Selenium downregulates auxin and ethylene biosynthesis in rice seedlings to modify primary metabolism and root architecture. Planta 250: 333-345, 2019.

Manokari M., Priyadharshini S., Arumugam N., Shekhawat M.S.: Mitigating in vitro induced macro- and micro-morphological anomalies using seismic stress in Vitex negundo L. - Plant Cell Tiss. Org. Cult. 143: 411-420, 2020.

Martínez-Estrada E., Islas-Luna B., Pérez-Sato J.A. et al.: Temporary immersion improves in vitro multiplication and acclimatization of Anthurium andreanum Lind. - Sci. Hortic.Amsterdam 249: 185-191, 2019.

Martins J.P.R., Martins A.D., Pires M.F. et al.: Anatomical and physiological responses of Billbergia zebrina (Bromeliaceae) to copper excess in a controlled microenvironment. - Plant Cell Tiss. Org. Cult. 126: 43-57, 2016.

Martins J.P.R., Rodrigues L.C.A., Santos E.R. et al.: Anatomy and photosystem II activity of in vitro grown Aechmea blanchetiana as affected by 1-naphthaleneacetic acid. - Biol. Plantarum 62: 211-221, 2018.

Martins J.P.R., Rodrigues L.C.A., Silva T.S. et al.: Sources and concentrations of silicon modulate the physiological and anatomical responses of Aechmea blanchetiana (Bromeliaceae) during in vitro culture. - Plant Cell Tiss. Org. Cult. 137: 397-410, 2019.
Martins J.P.R., Rodrigues L.C.A., Silva T.D.S. et al.: Modulation of the anatomical and physiological responses of in vitro grown Alcantarea imperialis induced by NAA and residual effects of BAP. - Ornam. Hortic. 26: 283-297, 2020a.

Martins J.P.R., Souza A.F.C., Rodrigues L.C.A. et al.: Zinc and selenium as modulating factors of the anatomy and physiology of Billbergia zebrina (Bromeliaceae) during in vitro culture. Photosynthetica 58: 1068-1077, 2020b.

Martins J.P.R., Verdoodt V., Pasqual M., De Proft M.: Impacts of photoautotrophic and photomixotrophic conditions on in vitro propagated Billbergia zebrina (Bromeliaceae). - Plant Cell Tiss. Org. Cult. 123: 121-132, 2015.

Mollo L., Martins M.C.M., Oliveira V.F. et al.: Effects of low temperature on growth and non-structural carbohydrates of the imperial bromeliad Alcantarea imperialis cultured in vitro. - Plant Cell Tiss. Org. Cult. 107: 141-149, 2011.

Murashige T., Skoog F.: A revised medium for rapid growth and bio assays with tobacco tissue cultures. - Physiol. Plantarum 15: 473-497, 1962.

Naciri R., Lahrir M., Benadis C. et al.: Interactive effect of potassium and cadmium on growth, root morphology and chlorophyll $a$ fluorescence in tomato plant. - Sci. Rep.-UK 11: 5384, 2021.

Oukarroum A., Schansker G., Strasser R.J.: Drought stress effects on photosystem I content and photosystem II thermotolerance analyzed using $\mathrm{Chl} a$ fluorescence kinetics in barley varieties differing in their drought tolerance. - Physiol. Plantarum 137: 188-199, 2009.

Pakum W., Inmano O., Kongbangkerd A.: TDZ and 2,4-D on in vitro propagation of panda plant from leaf explants. - Ornam. Hortic. 27: 41-48, 2021.

Priyadharshini S., Manokari M., Shekhawat M.S.: Attenuation of morpho-anatomical disorders of micropropagated plantlets of Crinum malabaricum Lekhak and Yadav using seismomechanical stimulation. - Braz. J. Bot. 43: 969-977, 2020.

Rastogi A., Zivcak M., Tripathi D.K. et al.: Phytotoxic effect of silver nanoparticles in Triticum aestivum: Improper regulation of photosystem I activity as the reason for oxidative damage in the chloroplast. - Photosynthetica 57: 209-216, 2019.

Raven J.A.: Speedy small stomata? - J. Exp. Bot. 65: 1415-1424, 2014.

Rezende R.A.L.S., Rodrigues F.A., Soares J.D.R. et al.: Salt stress and exogenous silicon influence physiological and anatomical features of in vitro-grown cape gooseberry. - Ciên. Rural 48: e20170176, 2018.

Rodrigues L.C.A., Martins J.P.R., Almeida Júnior O. et al.: Tolerance and potential for bioaccumulation of Alternanthera tenella Colla to cadmium under in vitro conditions. - Plant Cell Tiss. Org. Cult. 130: 507-519, 2017.

Rosa W.S., Martins J.P.R., Rodrigues E.S. et al.: Photosynthetic apparatus performance in function of the cytokinins used during the in vitro multiplication of Aechmea blanchetiana (Bromeliaceae). - Plant Cell Tiss. Org. Cult. 133: 339-350, 2018.

Sabatino L., La Bella S., Ntatsi G. et al.: Selenium biofortification and grafting modulate plant performance and functional features of cherry tomato grown in a soilless system. - Sci. Hortic.-Amsterdam 285: 110095, 2021.

Santos E.R., Martins J.P.R., Rodrigues L.C.D.A. et al.: Morphophysiological responses of Billbergia zebrina Lindl. (Bromeliaceae) in function of types and concentrations of carbohydrates during conventional in vitro culture. - Ornam. Hortic. 26: 18-34, 2020.

Seliem M.K., Abdalla N., El-Ramady H.R.: Response of Phalaenopsis orchid to selenium and bio-nano-selenium: in vitro rooting and acclimatization. - Environ. Biodivers. 
Soil Secur. 4: 277-290, 2020

Shafiq S., Adeel M., Raza H. et al.: Effects of foliar application of selenium in maize (Zea mays L.) under cadmium toxicity. Biol. Forum 11: 61-71, 2019.

Shekhawat M.S., Manokari M., Kannan N., Priyadharshini S.: Exogenous implication of seismic stress in attenuation of in vitro induced morpho-anatomical aberrations in Hemidesmus indicus (L.) R. Br. ex Schult. - S. Afr. J. Bot. 140: 385-392, 2021.

Silva D.P.C., Oliveira Paiva P.D., Herrera R.C. et al.: Effectiveness of silicon sources for in vitro development of gerbera. - Plant Cell Tiss. Org. Cult. 141: 77-85, 2020a.

Silva E.C., Sibov S.T., Santos F.C.A.D., Gonçalves L.A.: Influence of test tube sealing on the morpho-anatomy and ultrastructure of leaves of Aechmea bromeliifolia (Bromeliaceae) grown in vitro. - Rodriguésia 71: e00332018, 2020b.

Sotoodehnia-Korani S., Iranbakhsh A., Ebadi M. et al.: Selenium nanoparticles induced variations in growth, morphology, anatomy, biochemistry, gene expression, and epigenetic DNA methylation in Capsicum annuum; an in vitro study. Environ. Pollut. 265: 114727, 2020.

Sousaraei N., Mashayekhi K., Mousavizadeh S.J. et al.: Screening of tomato landraces for drought tolerance based on growth and chlorophyll fluorescence analyses. - Hortic. Environ. Biote. 62: 521-535, 2021.

Souza A.F.C., Martins J.P.R., Gontijo A.B.P.L., Falqueto A.R.: Selenium improves the transport dynamics and energy conservation of the photosynthetic apparatus of in vitro grown Billbergia zebrina (Bromeliaceae). - Photosynthetica 57: 931-941, 2019.

Srivastava A., Strasser R.J.: Stress and stress management of land plants during a regular day. - J. Plant Physiol. 148: 445, 1996.

Strasser R.J., Tsimilli-Michael M., Srivastava A.: Analysis of the chlorophyll $a$ fluorescence transient. - In: Papageorgiou G.C., Govindjee (ed.): Chlorophyll $a$ Fluorescence: A Signature of Photosynthesis. Advances in Photosynthesis and Respiration. Pp. 321-362. Springer, Dordrecht 2004.
Szarka V., Jokai Z., El-Ramady H. et al.: Biofortification of Stevia rebaudiana (Bert.) plant with selenium. - Environ. Biodivers. Soil Secur. 4: 19-31, 2020.

Tamaki V., Carvalho C.P., Lazarini R.A.D.M. et al.: [Storage of seeds harvested from different positions of the floral scape to obtain imperial bromeliad plants - Alcantarea imperialis.] Rodriguésia 71: e02832018, 2020. [In Portuguese]

Tian H., Lv B., Ding T. et al:: Auxin-BR interaction regulates plant growth and development. - Front. Plant Sci. 8: 2256, 2018.

Toungos M.D.: Plant growth substances in crop production: A review. - Int. J. Innov. Agric. Biol. Res. 6: 1-8, 2018.

Umar M., Uddin Z., Siddiqui Z.S.: Responses of photosynthetic apparatus in sunflower cultivars to combined drought and salt stress. - Photosynthetica 57: 627-639, 2019.

Versieux L.M., Wanderley M.G.L.: Bromélias - Gigantes do Brasil. [Giant Bromeliads from Brazil.] Pp. 200. Capim Macio \& Offset, Natal 2015. [In Portuguese]

Wang Y.W., Xu C., Lv C.F. et al.: Chlorophyll a fluorescence analysis of high-yield rice (Oryza sativa L.) LYPJ during leaf senescence. - Photosynthetica 54: 422-429, 2016.

Yusuf M.A., Kumar D., Rajwanshi R. et al.: Overexpression of $\gamma$-tocopherol methyl transferase gene in transgenic Brassica juncea plants alleviates abiotic stress: Physiological and chlorophyll $a$ fluorescence measurements. - BBABioenergetics 1797: 1428-1438, 2010.

Zhang H.H., Xu N., Wu X. et al.: Effects of four types of sodium salt stress on plant growth and photosynthetic apparatus in sorghum leaves. - J. Plant Interact. 13: 506-513, 2018.

Zhang Q., Peng S., Li Y.: Increase rate of light-induced stomatal conductance is related to stomatal size in the genus Oryza. J. Exp. Bot. 70: 5259-5269, 2019.

Zorger B.B., Arrivabene H.P. Milanez C.R.D.: Adaptive morphoanatomy and ecophysiology of Billbergia euphemiae, a hemiepiphyte Bromeliaceae. - Rodriguésia 70: e00592018, 2019.

(C) The authors. This is an open access article distributed under the terms of the Creative Commons BY-NC-ND Licence. 